\title{
Altered Neuronal Markers Following Treatment with Mood Stabilizer and Antipsychotic Drugs Indicate an Increased Likelihood of Neurotransmitter Release
}

\author{
Elizabeth Scarr, Brian Dean \\ Department of Psychiatry, Rebecca L. Cooper Research Laboratories, The Mental Health Research Institute, Melbourne Brain Centre, \\ The University of Melbourne, Parkville, Australia
}

\begin{abstract}
Objective: Given the ability of mood stabilizers and antipsychotics to promote cell proliferation, we wanted to determine the effects of these drugs on neuronal markers previously reported to be altered in subjects with psychiatric disorders.

Methods: Male Sprauge-Dawley rats were treated with vehicle (ethanol), lithium (25.5 mg per day), haloperidol $(0.1 \mathrm{mg} / \mathrm{kg})$, olanzapine $(1.0 \mathrm{mg} / \mathrm{kg})$ or a combination of lithium and either of the antipsychotic drugs for 28 days. Levels of cortical synaptic (synaptosomal associated protein-25, synaptophysin, vesicle associated protein and syntaxin) and structural (neural cell adhesion molecule and alpha-synuclein) proteins were determined in each treatment group using Western blots.

Results: Compared to the vehicle treated group; animals treated with haloperidol had greater levels of synaptosomal associated protein-25 $(p<0.01)$ and neural cell adhesion molecule $(p<0.05)$, those treated with olanzapine had greater levels of synaptophysin $(p<0.01)$ and syntaxin $(p<0.01)$. Treatment with lithium alone did not affect the levels of any of the proteins. Combining lithium and haloperidol resulted in greater levels of synaptophysin $(p<0.01)$, synaptosomal associated protein-25 $(p<0.01)$ and neural cell adhesion molecule $(p<0.01)$. The combination of lithium and olanzapine produced greater levels of synaptophysin $(p<0.01)$ and alpha-synuclein $(p<0.05)$.

Conclusion: Lithium alone had no effect on the neuronal markers. However, haloperidol and olanzapine affected different presynaptic markers. Combining lithium with olanzapine additionally increased alpha-synuclein. These drug effects need to be taken into account by future studies examining presynaptic and neuronal markers in tissue from subjects with psychiatric disorders.
\end{abstract}

KEY WORDS: Lithium; Antipsychotic agents; Nerve tissue proteins; SNARE proteins; Neural cell adhesion molecules.

\section{INTRODUCTION}

Bipolar disorder and schizophrenia are chronic, severe psychiatric disorders with poorly understood pathophysiologies and potentially life threatening sequelae. ${ }^{1,2)}$ A significant body of evidence points to abnormalities in many neurotransmitter systems contributing to the genesis of the symptomatology of psychiatric disorders (see for reviews on bipolar disorder; ${ }^{3,4)}$ see for reviews on schizophrenia $\left.{ }^{5-8}\right)$. Moreover, findings from post-mortem studies have suggested that changes in proteins associated with neurotransmitter release and synaptic structural integrity may underlie these changes in neurotransmitter systems

Received: August 31, 2011 / Accepted: October 10, 2011 Address for correspondence: Elizabeth Scarr, PhD Rebecca L. Cooper Research Laboratories, The Mental Health Research Institute, Melbourne Brain Centre, University of Melbourne, VIC 3010, Australia

Tel: +61-3-9389-2990, Fax: +61-3-9387-5061

E-mail: elscarr@unimelb.edu.au (schizophrenia, ${ }^{9-16)}$ bipolar disorder ${ }^{12,17-20)}$ ). Indeed it has been suggested that abnormal presynaptic function could be core to the pathophysiologies of psychiatric disorders. $^{21)}$

It is now recognised that treatments for disorders such as bipolar disorder and schizophrenia have many diverse effects. Significantly, mood stabilizer ${ }^{22)}$ and antipsychot$\mathrm{ics}^{23)}$ can promote neuronal, ${ }^{22)}$ neuroglial ${ }^{24)}$ and endothelial cell ${ }^{24)}$ proliferation in vivo. One outcome from significant changes in neuronal proliferation would be an increase in the proteins associated with neurotransmitter release, raising the issue of whether the changes seen in tissue from subjects with psychiatric disorders is due to the pharmacotherapy they received. Therefore, we have determined whether treating rats with the mood stabilizer lithium, the typical antipsychotic haloperidol (conventional antipsychotics are used to treat acute mania ${ }^{25}$ ), the atypical antipsychotic olanzapine (used to treat patients who only partially respond to mood stabilizers ${ }^{26}$ ) or con- 
comitant use of mood stabilizers with antipsychotics (as used in treating schizophrenia ${ }^{27,28)}$ ) affects levels of proteins regarded as markers for presynaptic neurons or neuronal structural integrity. These studies were completed in the cortex because this region of the human central nervous system is known to be affected by the pathologies of bipolar disorder and schizophrenia. ${ }^{4,29)}$

\section{METHODS}

\section{Materials}

Haloperidol, goat serum, sodium orthovanadate, anti-neural cell adhesion molecule (NCAM) antibody (C9672) and all general laboratory grade chemicals were obtained from Sigma-Aldrich Pty. (North Ryde, Australia). All electrophoresis grade chemicals and materials were obtained from Bio-Rad Laboratories Pty., Ltd. (Gladesville, Australia) and GE Healthcare Pty., Ltd. (Rydalmere, Australia), whilst the Pierce Supersignal enhanced chemiluminescence (ECL) was obtained from Thermo Fisher Scientific Pty., Ltd. (Scoresby, Australia). Antibodies to synaptosomal-associated protein-25 (SNAP-25) (MAB331), synaptophysin (MAB368, vesicle associated protein [VAMP; MAB333]) and syntaxin (MAB336) were obtained from Chemicon (Merck Millipore, Kilsyth, Australia). The mouse anti- alpha-synuclein (610786) was obtained from BD Biosciences (North Ryde, Australia) and goat anti-mouse IgG:HRP (P0447) from DAKO Pty., Ltd. (Bella Vista, Australia). The rodent chow was milled by Specialty Feeds (Glen Forest, Australia). Olanzapine was a generous gift from Eli Lilly (Indianapolis, IN, USA).

\section{Drug Treatment}

After obtaining consent from the University of Melbourne Animal Experimental Ethics Committee, all drug administration procedures and experimental protocols were performed at the Mental Health Research Institute in accordance to the Australian Code of Practice for the Care and Use of Animals for Scientific Purposes (1990) set out by the National Health and Medical Research Council of Australia and the Victorian Prevention of cruelty to animals act and regulations. Every effort was made to minimise the number of animals.

Tissue for this study came from male Sprauge-Dawley rats (average starting weight $213 \mathrm{~g}$ ) obtained from the breeding colony at Melbourne University. The rats were randomly assigned to a treatment group in blocks of ten, with ad libitum access to food and water and maintained at $19 \pm 4^{\circ} \mathrm{C}$ on a 12 hour light/dark cycle. The groups were assigned one of six treatment regimens for a period of 28 days, during which time they received lithium, haloperidol, olanzapine, a combination of lithium and haloperidol or a combination of lithium and olanzapine (Table 1). To counteract the potential lithium toxicity all animals were given ad libitum access to $0.9 \%$ saline, in addition to drinking water and rodent chow. Once assigned to their treatment groups, the animals were allowed to acclimatise for three days with ad libitum access to pre-weighed food, drinking water and $0.9 \%$ saline solution to establish a baseline from which to calculate initial doses. The antipsychotic drug doses were chosen because of their ability to occupy D2 receptors at clinically comparable levels. ${ }^{30}$ At the end of the treatment period, the brains were removed and dissected, the dissected brains were snap frozen on dry ice and stored at $-80^{\circ} \mathrm{C}$ until required. A terminal bleed was acquired and blood serum levels of haloperidol, olanzapine and lithium determined by the Victorian Institute of Forensic Medicine.

Importantly, levels of lithium in the terminal bleeds (0.6-0.8 $\mathrm{mMol} / \mathrm{L})$ were measured using atomic absorption spectroscopy and were found to be within the ideal therapeutic range in humans $(0.5-1.0 \mathrm{mMol} / \mathrm{L})$. Levels of haloperidol and olanzapine were measured using selected ion mass spectrometry with capillary chromatography and quantitative high pressure liquid chromatography respectively. In both instances the levels were found to be below the limits of detection $(0.005 \mathrm{mg} / \mathrm{L}$ for haloperidol and $0.05 \mathrm{mg} / \mathrm{L}$ for olanzapine), which are also the clinical

Table 1. Summary of the treatment regimens used to study the effects of lithium, antipsychotics and a combination of the mood stabilizers and antipsychotic on neuronal markers

\begin{tabular}{|c|c|c|c|c|c|c|}
\hline Variables & Control & $\begin{array}{l}\text { Haloperidol } \\
(0.1 \mathrm{mg} / \mathrm{kg})\end{array}$ & $\begin{array}{l}\text { Olanzapine } \\
(1.0 \mathrm{mg} / \mathrm{kg})\end{array}$ & Lithium & Haloperidol+lithium & Olanzapine + lithium \\
\hline Rodent chow & AIN93G & AIN93G & AIN93G & $\begin{array}{l}\text { AIN93G+ } 1.7 \mathrm{~g} \\
\mathrm{Li}_{2} \mathrm{CO}_{3} / \text { kilo chow }\end{array}$ & $\begin{array}{l}\text { AlN93G + } 1.7 \mathrm{~g} \\
\mathrm{Li}_{2} \mathrm{CO}_{3} / \text { kilo chow }\end{array}$ & $\begin{array}{l}\text { AIN93G }+1.7 \mathrm{~g} \\
\mathrm{Li}_{2} \mathrm{CO}_{3} / \text { kilo chow }\end{array}$ \\
\hline Water & +ethanol & +haloperidol & +olanzapine & +ethanol & +haloperidol & +olanzapine \\
\hline $0.9 \%$ saline & +ethanol & +haloperidol & +olanzapine & +ethanol & +haloperidol & + olanzapine \\
\hline
\end{tabular}

AIN93G, standard rodent diet formulation. 
therapeutic levels.

There were no significant differences in mean body weight between the different groups created ad hoc and subsequently treated with the differing drug regimes $(\mathrm{F}=1.932$, degree of freedom $[\mathrm{df}]=5,54, p=0.1040)$. By contrast, at the end of the treatment periods there was significant variation in the mean body weight between the different groups $(\mathrm{F}=28.95, \mathrm{df}=5,54, p<0.0001)$ due to all the groups that had received lithium gaining less weight than the vehicle group (weight gained, mean \pm standard error of the mean (SEM); vehicle $=205 \pm 9.8 \mathrm{~g}$, lithium= $135 \pm 6.4 \mathrm{~g}$, lithium plus haloperidol $=143 \pm 4.3 \mathrm{~g}$, lithium plus olanzapine $=121 \pm 5.5 \mathrm{~g} ; p<0.05$ ). The lower weight gain could be partly accounted for by the variation in daily food intake across the groups (Kruskal-Wallis statistic=23.79, $p=0.0002$ ). Post- hoc tests showed that groups treated with lithium or lithium and olanzapine consumed less food per day than the vehicle group (mean \pm SEM; vehicle $=28 \pm 0.5 \mathrm{~g} /$ day, lithium $=18.9 \pm 1.5$ $\mathrm{g}$ /day, lithium plus olanzapine $=21.5 \pm 1.1 \mathrm{~g} /$ day; $p<0.05$ ).

\section{Tissue Processing}

Homogenates were prepared from the cortices (between bregma +5.20 and +3.20 having first stripped off the olfactory tubercules) of all rats in the treatment groups, at 5\% w/v in $10 \mathrm{mM}$ Tris ( $\mathrm{pH} 7.4)$, containing $1 \mathrm{mM}$ fresh sodium orthovanadate (Sigma-Aldrich). Protein concentrations were determined using the Bio-Rad DC modified Lowry protein assay adapted for the microplate and the homogenates diluted in reducing buffer to give final protein levels of $1.0 \mathrm{mg} / \mathrm{ml}$. Samples were run in duplicate and the proteins (20 $\mu \mathrm{g}$ total protein per lane) were separated using polyacrylamide gel electrophoresis (4\% stacking gel, empirically determined running gel) at a constant voltage of $150 \mathrm{~V}$. They were then transferred to nitrocellulose membranes overnight in Towbin transfer buffer $^{31)}$ at a constant current of $40 \mathrm{~mA}$.

\section{Western Blots}

The conditions under which nitrocellulose membranes were probed for SNAP-25, synaptophysin, syntaxin, VAMP, NCAM and alpha-synuclein were empirically determined to ensure the measurements were conducted within the linear range of detection for each antibody and are summarized in Table 2. In all cases, after confirming protein loading with ponceau S staining, the nitrocellulose membranes were blocked for an hour at room temperature, in a suitable buffer, before being incubated with the appropriate primary antibody for one or two hours at room temperature. This was followed by incubation with a secondary antibody against the appropriate host conjugated to horseradish peroxidase for an hour at room temperature. Visualization of the antigenic reaction was achieved by the ECL technique using Pierce Supersignal ${ }^{\mathbb{R}}$ West Pico chemiluminescent substrate. The membranes were imaged using a Kodak Image Station 440CF (Kodak, PerkinElmer, Glen Waverley, VIC, Australia) and the sum intensity of the antigenic bands determined using Kodak 1D software (Kodak).

To control for inter-blot variation, an internal control membrane preparation was run in 12 wells on two gels to establish both intra- and inter-blot variation for the measurement of each protein. This internal control was subsequently run (in duplicate) on every gel. Gels were exposed such that the optical density of the internal control fell within the range established by the mean \pm 2 SDs of the initial measurements. These internal control values were used to standardize the data by expressing it as ratio of internal control.

As reported previously for these antibodies, ${ }^{18,19)}$ SNAP25 , synaptophysin, VAMP and alpha-synuclein produced a single band at the appropriate molecular weight in cortical homogenates. For syntaxin and NCAM, more than one band was visualised in the cortical homogenates; with the NCAM antibody, two bands, one at 140 and one at 180

Table 2. Conditions under which nitrocellulose membranes were probed for SNAP-25, synaptophysin, syntaxin, VAMP, alpha-synuclein and NCAM. Antibody solutions were made up in the blocking buffer

\begin{tabular}{|c|c|c|c|c|c|c|}
\hline Variables & SNAP-25 & Synaptophysin & Syntaxin & VAMP & $\alpha$-synuclein & NCAM \\
\hline Resolving gel (\%) & 15 & 15 & 10 & 15 & 12 & 15 \\
\hline Blocking buffer & 5\% NFMP; $1 \mathrm{hr}$; RT & 5\% NFMP; $1 \mathrm{hr} ; \mathrm{RT}$ & TTBS; 1 hr; RT & TTBS; $1 \mathrm{hr}$; RT & TTBS; $1 \mathrm{hr}$; RT & 5\% NFMP; $1 \mathrm{hr}$; RT \\
\hline Primary antibody & 1/1,000; 1 hr; RT & 1/20,000; 1 hr; RT & 1/4,000; $1 \mathrm{hr} ; \mathrm{RT}$ & 1/2,000; $1 \mathrm{hr} ; \mathrm{RT}$ & 1/2,000; $1 \mathrm{hr} ; \mathrm{RT}$ & 1/10,000; 2 hr; RT \\
\hline Washes & $4 \times 5 \mathrm{~min} ; \mathrm{TTBS}$ & $4 \times 5 \mathrm{~min} ; \mathrm{TTBS}$ & $4 \times 5$ min; TTBS & $4 \times 5$ min; TTBS & $4 \times 5$ min; TTBS & $4 \times 5$ min; TTBS \\
\hline Secondary antibody & 1/2,000; 1 hr; RT & 1/4,000; 1 hr; RT & 1/2,000; 1 hr; RT & 1/2,000; $1 \mathrm{hr} ; \mathrm{RT}$ & 1/2,000; $1 \mathrm{hr} ; \mathrm{RT}$ & 1/2,000; $1 \mathrm{hr} ; \mathrm{RT}$ \\
\hline Washes & $4 \times 5 \mathrm{~min} ; \mathrm{TTBS}$ & $4 \times 5 \mathrm{~min} ; \mathrm{TTBS}$ & $4 \times 5$ min; TTBS & $4 \times 5 \mathrm{~min}$; TTBS & $4 \times 5$ min; TTBS & $4 \times 5$ min; TTBS \\
\hline
\end{tabular}

SNAP-25, synaptosomal associated protein-25: VAMP, vesicle associated protein; NCAM, neural cell adhesion molecule: hr, hour(s); min minute(s); TTBS, 0.1\% Tween-20 in Tris buffered saline; NFMP, non-fat milk powder, made up in TTBS; RT, room temperature. Resolving gel refers to the percentage of acrylamide. 
kDa were observed. Neither the polysialylated nor any of the smaller, soluble forms of NCAM were observed in these samples. The syntaxin antibody revealed two immunogenic bands, one at 33 and one at $35 \mathrm{kDa}$.

\section{Statistics}

The D'Agostino \& Pearson omnibus normality test was used to determine whether the data were normally
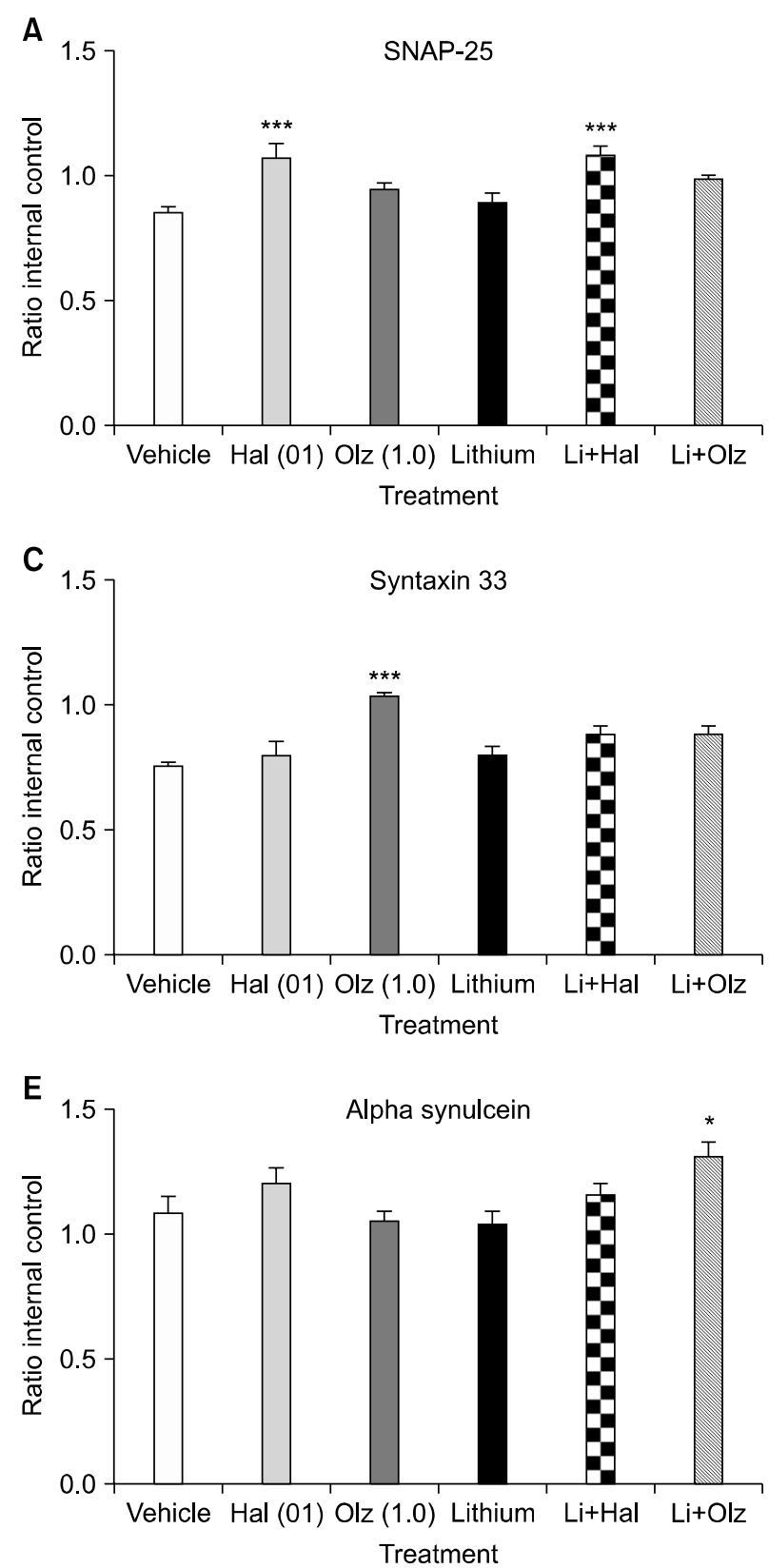

distributed. Grubb's test was used to determine whether any of the data sets contained outlying points. The source of variation with treatment was identified using a one-way ANOVA followed by Dunnett's multiple comparison test, with all treatment groups being compared to the vehicle group. The average rate of food consumption was compared across the treatment groups using the KruskalWallis test, with post-hoc testing being conducted using
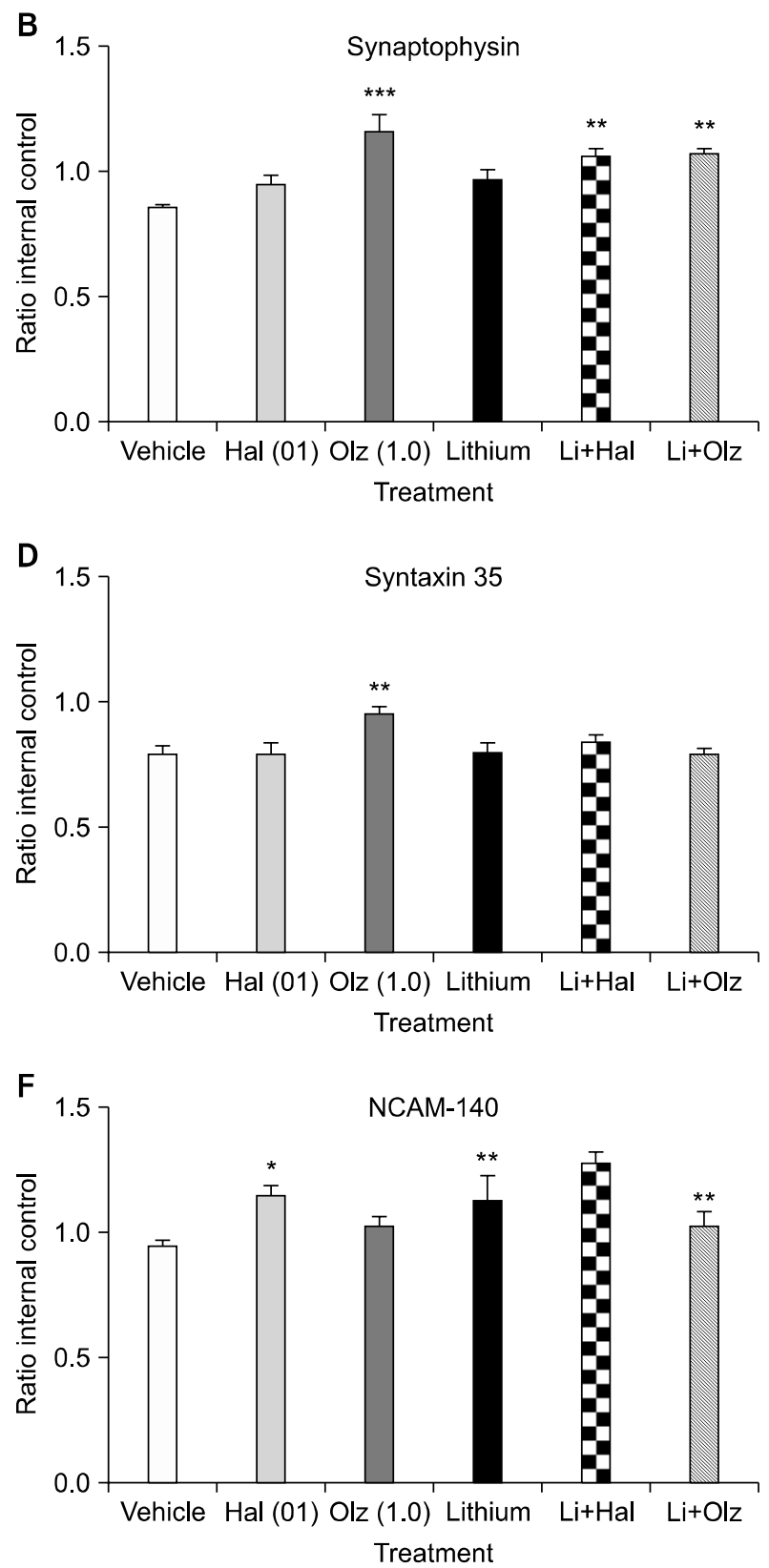

Fig. 1. Graphical representations of the levels (mean \pm standard error of the mean) of SNAP-25 (A), synaptophysion (B), syntaxin 33kDa (C), syntaxin $35 \mathrm{kDa}(\mathrm{D})$, alpha-synulcein (E), NCAM-140 (F) that were affected by treatment with haloperidol or olanzapine either alone or in combination with lithium. ${ }^{*} p<0.05,{ }^{* *} p<0.01,{ }^{* *} p<0.001$, compared to vehicle. SNAP-25, synatposomal associated protein-25; NCAM-140, neural cell adhesion molecule 140; Hal, haloperidol; Olz, olanzapine; Li, lithium. 
Dunn's multiple comparison test. All analyses were carried out using GraphPad Prism Version 5.0 for Windows (GraphPad Software Inc., San Diego, CA, USA).

\section{RESULTS}

\section{SNAP-25}

There was significant variance in levels of SNAP-25 with drug treatment $(\mathrm{F}=6.56, \mathrm{df}=5,54, p<0.0001)$, which was due to animals treated with $0.1 \mathrm{mg} / \mathrm{kg}$ haloperidol $(p$ $<0.001$ ) and a combination of lithium and $0.1 \mathrm{mg} / \mathrm{kg}$ haloperidol $(p<0.001)$ having higher levels of the protein compared to the vehicle group (Fig. 1A).

\section{Synaptophysin}

Levels of synaptophysin varied with treatment $(\mathrm{F}=$ $6.44, \mathrm{df}=5,54, p<0.0001)$ as a result of higher levels of the protein in rats treated with $1.0 \mathrm{mg} / \mathrm{kg}$ olanzapine $(p$ $<0.001$ ), a combination of lithium and haloperidol $(p$ $<0.01)$ or a combination of lithium and olanzapine $(p$ $<0.01$, Fig. 1B).

\section{Syntaxin}

Levels of syntaxin 33 and 35 both varied with drug treatment ( $33 \mathrm{kDa} ; \mathrm{F}=7.07, \mathrm{df}=5,54, p<0.0001: 35 \mathrm{kDa}$; $\mathrm{F}=4.48, \mathrm{df}=5,54, p<0.005)$ due to higher levels of both isoforms of the protein after treatment with olanzapine ( $p$ $<0.001$, Fig. 1C, D).

\section{VAMP}

None of the treatment regimens caused a variation in levels of VAMP $(\mathrm{F}=0.38, \mathrm{df}=5,54, p=0.86$; ratio internal control mean \pm SEM: vehicle $=0.974 \pm 0.061,0.1 \mathrm{mg} / \mathrm{kg}$ haloperidol $=1.040 \pm 0.039,1 \mathrm{mg} / \mathrm{kg}$ olanzapine $=0.964 \pm$ $0.031,25.5 \mathrm{mg} /$ day lithium $=0.990 \pm 0.035$, haloperidol and lithium $=1.01 \pm 0.035$, lithium and olanzapine $=1.00 \pm$ 0.055).

\section{Alpha-synuclein}

Levels of alpha-synuclein varied with drug treatment $(\mathrm{F}=3.87, \mathrm{df}=5,54, p<0.005)$ due to higher levels of the protein in rats treated with a combination of lithium and olanzapine $(p<0.05$, Fig. 1E).

\section{NCAM}

Levels of NCAM-140 varied with treatment $(\mathrm{F}=4.55$, $\mathrm{df}=5,54, p<0.005$ ), with increased levels of the protein in rats treated with haloperidol $(p<0.05)$ or a combination of lithium and haloperidol ( $p<0.001$, Fig. 1F). By contrast, none of the drug treatments had any effect on levels of NCAM-180 $(\mathrm{F}=0.823, \mathrm{df}=5,54, \mathrm{p}=0.54$; ratio internal control mean \pm SEM: vehicle $=1.22 \pm 0.064,0.1 \mathrm{mg} / \mathrm{kg}$ haloperidol $=1.17 \pm 0.074,1 \mathrm{mg} / \mathrm{kg}$ olanzapine $=1.25 \pm 0.055$, $25.5 \mathrm{mg}$ /day lithium $=1.36 \pm 0.110$, haloperidol and lithium $=1.36 \pm 0.108$, lithium and olanzapine $=1.17 \pm 0.13$ ).

\section{DISCUSSION}

This study has shown that treatment with antipsychotic drugs alone or in conjunction with the archetypal mood stabilizer lithium has complex effects on markers of neurotransmitter release and structural proteins (Fig. 2).

\section{Effects of Drug Treatment on Markers of Neurotransmitter Release}

The soluble N-ethylmaleimide-sensitive fusion protein attachment protein receptor (SNARE) protein SNAP-25 was increased after treatment with haloperidol alone and haloperidol in combination with lithium. Significantly, the combined treatment with lithium and haloperidol did not increase levels of SNAP-25 above that which occurred after treatment with haloperidol $(t=0.1569, \mathrm{df}=18, p>$ 0.05 ) suggesting that the changes in SNAP-25 resulted from treatment with haloperidol. Thus, our data partly agrees with previous studies which reported that haloperidol treatment increased levels of SNAP-25, VAMP and

\section{Lithium}
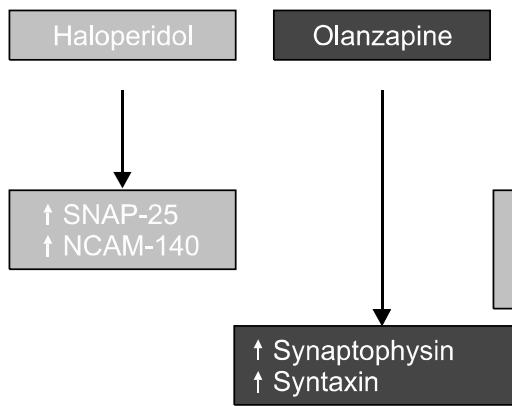

Fig. 2. A schematic representation of the changes in neuronal markers following treatment with antipsychotics, either alone or in combination with lithium. Each treatment is colour coded and the arrows indicate the direction of change in the level of that marker following the specific regimen. SNAP-25, synaptosomal associated protein-25; NCAM-140, neural cell adhesion molecule 140. 
syntaxin mRNA ${ }^{32,33)}$ and protein. ${ }^{16)}$ Significantly, unlike the previous studies ${ }^{16,32,33)}$, our study did not find that treatment with haloperidol increased levels of VAMP or syntaxin. This could simply be a drug-dose effect as the earlier studies give 100-250x the dose of haloperidol used in this study. Given the doses in our study are more closely related to the dopamine D2 receptor blockade that gives optimum outcomes in humans, ${ }^{30)}$ it may be that changes in syntaxin are only achieved with supra-pharmacological doses of antipsychotic drugs. Moreover, the lack of change seen in syntaxin protein following haloperidol treatment is in agreement with a recent study. ${ }^{34)}$ Our finding that lithium does not affect levels of SNAP-25 is in agreement with a previous study ${ }^{35)}$ but differs from another study that suggested lithium treatment decreased SNAP-25 levels. ${ }^{36)}$ Therefore, whilst limited, the available data would favour the argument that lithium treatment does not change levels of cortical SNAP-25.

Levels of synaptophysin were shown to be increased after treatment with olanzapine whilst combined treatments with lithium and haloperidol or olanzapine also increased levels of synaptophysin in the cortex. This somewhat complex outcome was due to the combined treatment of lithium and haloperidol increasing levels of synaptophy$\sin (t=2.214, \mathrm{df}=18, p<0.05)$ above that seen after treatment with haloperidol alone, whereas combined treatment with lithium and olanzapine did not increase levels of synaptophysin beyond that after olanzapine treatment $(t=$ $1.011, \mathrm{df}=18, p>0.05$ ). These data emphasise the complex interactions between antipsychotic drugs and lithium. Our data showing lithium does not increase levels of synaptophysin is in line with previous studies. ${ }^{35,37,38)}$ By contrast, our data suggests that the previously reported haloperidol-induced change in synaptophysin $\mathrm{mRNA}^{39)}$ may not have been accompanied by a change in synaptophysin protein.

Olanzapine was the only treatment that caused an increase in either isoform of syntaxin. Syntaxin levels were not increased after treatment with olanzapine and lithium suggesting lithium may block this action of olanzapine.

Importantly, SNAP-25, synaptophysin, syntaxin and VAMP all play critical roles in quantal neurotransmitter release by regulating the fusion of filled synaptic vesicles with the neuronal membrane. This whole process is dependent upon the formation of SNARE complex, ${ }^{40)}$ which is made up of three proteins, SNAP-25 and syntaxin (located on the neuronal membrane) and VAMP (located in the vesicle membrane) in a $1: 1: 1$ stoichiometry. Significantly, we have shown that levels of two of these proteins are increased following treatment with either haloperidol or olanzapine. Furthermore, synaptophysin acts as a chaperone for VAMP, potentially regulating the formation of SNARE complexes, ${ }^{41)}$ with overexpression of synaptophysin increasing neurotransmitter secretion; ${ }^{42)}$ its expression is also increased following antipsychotic drug treatment. Thus, one unifying hypothesis from our study is that the changes observed in these neuronal markers after different antipsychotic drug treatments all have the potential to enhance neurotransmitter release.

\section{Effects of Drug Treatment on Markers of Neuronal Structure}

Alpha-synucelin was increased after treatment with the combination of lithium and olanzapine. We are aware of no other studies reporting these drug effects. Alpha-synuclein is predominantly expressed at presynaptic terminals and is thought to be regulated by synaptic activity- and neurite growth-promoting signals. ${ }^{43)}$ Furthermore, it has been shown to be substantially upregulated during synaptic modification ${ }^{44)}$ and to enhance synaptic transmission $^{45)}$ by promoting formation of SNARE complexes. ${ }^{46)}$ Mice that are null for alpha-synuclein showed increased activity-dependent neurotransmitter release ${ }^{47)}$ but reduced neurotransmitter release in response to repeated stimulation. ${ }^{48,49)}$ Thus, it is possible that the increased alpha-synuclein expression seen following treatment with the combination of lithium and olanzapine could result in increased cortical transmission, particularly when coupled with an increased probability of forming SNARE complexes due to the increased levels of synaptophysin resulting from treatment with olanzapine.

Finally, levels of NCAM-140, but not NCAM-180, were increased after treatment with haloperidol alone and combined lithium and haloperidol. These data agree with another study that showed that treatment with lithium did not affect levels of NCAM. ${ }^{36)}$ However, these data differ from a previous study showing that treatment with olanzapine, but not haloperidol, caused an increase in polysialylated $\mathrm{NCAM}^{50)}$ indicating that different antipsychotic drugs may have different effects on different forms of NCAM. Moreover, the combined treatment increased levels of NCAM-140 $(t=2.215, \mathrm{df}=18, p<0.05)$ above that achieved after treatment with haloperidol alone. Importantly, the different isoforms of NCAM have dissimilar functions; ${ }^{51)}$ it is currently thought that the relative levels of the 180 and 140 isoforms is a determining factor in synaptic activity. ${ }^{52,53)}$ In particular, NCAM-140 is required for the breakdown and reforming of synaptic 
connections as well as increasing neurite outgrowth. ${ }^{51,54)}$ Thus, it is possible that treatment with haloperidol, either alone or in combination with lithium, results in an increased synaptic plasticity of the cortex, which would be compatible with the increased levels of presynaptic markers also seen after these treatments.

In summary, none of the treatments caused increases in all of the markers of neurotransmitter-related proteins or mature neurons. Rather, the predominant effect of treatment with antipsychotics, alone and in combination with lithium, was to cause changes that could increase the probability of cortical synaptic transmission. The only novel effect following lithium treatment was seen when it was combined with olanzapine, resulting in increased levels of alpha-synuclein. One of the functions of alpha-synuclein is to regulate the activity of the noradrenaline transporter. ${ }^{55)}$ It has recently been shown that treatment with desipramine increases levels of alpha-synuclein and the noradrenaline transporter whilst improving the performance of Wistar-Kyoto rats in the forced swim test. ${ }^{56)}$ Thus, the ability of adjunctive olanzapine to improve depressive symptoms in bipolar disorder may be linked to modulation of the activity of the noradrenaline transporter by alpha-synuclein.

Given the increases seen in SNAP-25, synaptophysin, syntaxin, alpha-synuclein and NCAM following treatment with antipsychotic drugs both with and without concomitant lithium, data from post-mortem studies need to be interpreted with care and should be accompanied by pharmacological experiments investigating the effects of the drugs used for treating that specific cohort on the neuronal markers of interest.

This study provided a novel insight into the potential mechanisms of action by which psychotropic drugs may bring about therapeutic benefits for people with major psychiatric disorders. We have shown that antipsychotic drugs have the potential to alter both synaptic plasticity and transmission. Thus, the concept that abnormalities in pre-synaptic neuronal function may be central to the pathophysiology of disorders such as schizophrenia ${ }^{21)}$ can now be augmented with the argument that antipsychotic drugs may act, at least in part, to reverse some of these pre-synaptic abnormalities.

\section{Acknowledgments}

The authors would like to thank Susan Juzva, Suzette Sheppard, Geoff Pavey and Simone Boer for their assistance. This study was funded by Lilly-MAP and supported by Operational Infrastructure Support (OIS) from the Victorian State Government. Olanzapine was a generous gift from Eli Lilly, Indianapolis. Partial funding for the Kodak Image Station 440CF was provided by Equity Trustees. ES was the Royce Abbey Postdoctoral Fellow funded by Australian Rotary Health Research Fund. BD is a NH\&MRC Senior Research Fellow (\#APP1002240).

\section{REFERENCES}

1. Pompili M, Rihmer Z, Innamorati M, Lester D, Girardi P, Tatarelli R. Assessment and treatment of suicide risk in bipolar disorders. Expert Rev Neurother 2009;9:109-136.

2. Montross LP, Kasckow J, Golshan S, Solorzano E, Lehman D, Zisook S. Suicidal ideation and suicide attempts among middle-aged and older patients with schizophrenia spectrum disorders and concurrent subsyndromal depression. J Nerv Ment Dis 2008;196:884-890.

3. Newberg AR, Catapano LA, Zarate CA, Manji HK. Neurobiology of bipolar disorder. Expert Rev Neurother 2008;8: 93-110.

4. Dean B. Changes in the molecular structure of the brain in bipolar disorder: findings using human postmortem brain tissue. World J Biol Psychiatry 2002;3:125-132.

5. Scarr E, Dean B. Role of the cholinergic system in the pathology and treatment of schizophrenia. Expert Rev Neurother 2009;9:73-86.

6. Lewis DA, González-Burgos G. Neuroplasticity of neocortical circuits in schizophrenia. Neuropsychopharmacology 2008;33:141-165.

7. Geyer MA, Vollenweider FX. Serotonin research: contributions to understanding psychoses. Trends Pharmacol Sci 2008;29:445-453.

8. Laruelle M, Frankle WG, Narendran R, Kegeles LS, AbiDargham A. Mechanism of action of antipsychotic drugs: from dopamine $D(2)$ receptor antagonism to glutamate NMDA facilitation. Clin Ther 2005;27(Suppl A):S16-S24.

9. Honer WG, Falkai P, Young C, Wang T, Xie J, Bonner J, et al. Cingulate cortex synaptic terminal proteins and neural cell adhesion molecule in schizophrenia. Neuroscience 1997;78:99-110.

10. Gabriel SM, Haroutunian V, Powchik P, Honer WG, Davidson M, Davies P, et al. Increased concentrations of presynaptic proteins in the cingulate cortex of subjects with schizophrenia. Arch Gen Psychiatry 1997;54:559-566.

11. Thompson PM, Sower AC, Perrone-Bizzozero NI. Altered levels of the synaptosomal associated protein SNAP-25 in schizophrenia. Biol Psychiatry 1998;43:239-243.

12. Fatemi SH, Earle JA, Stary JM, Lee S, Sedgewick J. Altered levels of the synaptosomal associated protein SNAP-25 in hippocampus of subjects with mood disorders and schizophrenia. Neuroreport 2001;12:3257-3262.

13. Honer WG, Falkai P, Bayer TA, Xie J, Hu L, Li HY, et al. Abnormalities of SNARE mechanism proteins in anterior frontal cortex in severe mental illness. Cereb Cortex 2002; 12:349-356.

14. Pennington K, Dicker P, Dunn MJ, Cotter DR. Proteomic analysis reveals protein changes within layer 2 of the insular cortex in schizophrenia. Proteomics 2008;8:5097-5107.

15. Gibbons AS, Thomas EA, Dean B. Regional and duration of illness differences in the alteration of NCAM-180 mRNA expression within the cortex of subjects with schizophrenia. Schizophr Res 2009;112:65-71. 
16. Barakauskas VE, Beasley CL, Barr AM, Ypsilanti AR, Li $\mathrm{HY}$, Thornton $\mathrm{AE}$, et al. A novel mechanism and treatment target for presynaptic abnormalities in specific striatal regions in schizophrenia. Neuropsychopharmacology 2010;35: 1226-1238.

17. Beasley CL, Honer WG, Bergmann K, Falkai P, Lütjohann $\mathrm{D}$, Bayer TA. Reductions in cholesterol and synaptic markers in association cortex in mood disorders. Bipolar Disord 2005; 7:449-455.

18. Scarr E, Gray L, Keriakous D, Robinson PJ, Dean B. Increased levels of SNAP-25 and synaptophysin in the dorsolateral prefrontal cortex in bipolar I disorder. Bipolar Disord 2006;8:133-143.

19. Gray LJ, Dean B, Kronsbein HC, Robinson PJ, Scarr E. Region and diagnosis-specific changes in synaptic proteins in schizophrenia and bipolar I disorder. Psychiatry Res 2010;178:374-380.

20. Kim HW, Rapoport SI, Rao JS. Altered expression of apoptotic factors and synaptic markers in postmortem brain from bipolar disorder patients. Neurobiol Dis 2010;37:596603.

21. Dean B. Signal transmission, rather than reception, is the underlying neurochemical abnormality in schizophrenia. Aust N Z J Psychiatry 2000;34:560-569.

22. Chen G, Rajkowska G, Du F, Seraji-Bozorgzad N, Manji HK. Enhancement of hippocampal neurogenesis by lithium. J Neurochem 2000;75:1729-1734.

23. Wang HD, Dunnavant FD, Jarman T, Deutch AY. Effects of antipsychotic drugs on neurogenesis in the forebrain of the adult rat. Neuropsychopharmacology 2004;29:1230-1238.

24. Kodama M, Fujioka T, Duman RS. Chronic olanzapine or fluoxetine administration increases cell proliferation in hippocampus and prefrontal cortex of adult rat. Biol Psychiatry 2004;56:570-550.

25. Tohen M, Jacobs TG, Feldman PD. Onset of action of antipsychotics in the treatment of mania. Bipolar Disord 2000;2:261-268.

26. Tohen M, Chengappa KN, Suppes T, Zarate CA Jr, Calabrese JR, Bowden CL, et al. Efficacy of olanzapine in combination with valproate or lithium in the treatment of mania in patients partially nonresponsive to valproate or lithium monotherapy. Arch Gen Psychiatry 2002;59:62-69.

27. Citrome L, Jaffe A, Levine J, Allingham B. Use of mood stabilizers among patients with schizophrenia, 1994-2001. Psychiatr Serv 2002;53:1212.

28. Haw C, Stubbs J. A survey of the off-label use of mood stabilizers in a large psychiatric hospital. J Psychopharmacol 2005;19:402-407.

29. Johnston-Wilson NL, Sims CD, Hofmann JP, Anderson L, Shore AD, Torrey EF, et al. Disease-specific alterations in frontal cortex brain proteins in schizophrenia, bipolar disorder, and major depressive disorder. The Stanley Neuropathology Consortium. Mol Psychiatry 2000;5:142-149.

30. Kapur S, VanderSpek SC, Brownlee BA, Nobrega JN. Antipsychotic dosing in preclinical models is often unrepresentative of the clinical condition: a suggested solution based on in vivo occupancy. J Pharmacol Exp Ther 2003; 305:625-631.

31. Towbin H, Staehelin T, Gordon J. Electrophoretic transfer of proteins from polyacrylamide gels to nitrocellulose sheets: procedure and some applications. Proc Natl Acad Sci U S A 1979;76:4350-4354.

32. MacDonald ML, Eaton ME, Dudman JT, Konradi C. Antipsychotic drugs elevate mRNA levels of presynaptic proteins in the frontal cortex of the rat. Biol Psychiatry
2005;57:1041-1051.

33. Nakahara T, Nakamura K, Tsutsumi T, Hashimoto K, Hondo $\mathrm{H}$, Hisatomi S, et al. Effect of chronic haloperidol treatment on synaptic protein mRNAs in the rat brain. Brain Res Mol Brain Res 1998;61:238-242.

34. Castillo MA, Ghose S, Tamminga CA, Ulery-Reynolds PG. Deficits in syntaxin 1 phosphorylation in schizophrenia prefrontal cortex. Biol Psychiatry 2010;67:208-216.

35. Cordeiro ML, Umbach JA, Gundersen CB. Lithium ions enhance cysteine string protein gene expression in vivo and in vitro. J Neurochem 2000;74:2365-2372.

36. Plenge P, Mellerup ET, Jørgensen OS. Lithium treatment regimens induce different changes in [3H]paroxetine binding protein and other rat brain proteins. Psychopharmacology (Berl) 1992;106:131-135.

37. Vawter MP, Thatcher L, Usen N, Hyde TM, Kleinman JE, Freed WJ. Reduction of synapsin in the hippocampus of patients with bipolar disorder and schizophrenia. Mol Psychiatry 2002; 7:571-578.

38. Zucker M, Weizman A, Harel D, Rehavi M. Changes in vesicular monoamine transporter (VMAT2) and synaptophysin in rat Substantia nigra and prefrontal cortex induced by psychotropic drugs. Neuropsychobiology 2001;44:187-191.

39. Eastwood SL, Heffernan J, Harrison PJ. Chronic haloperidol treatment differentially affects the expression of synaptic and neuronal plasticity-associated genes. Mol Psychiatry 1997;2: 322-329.

40. Söllner T, Whiteheart SW, Brunner M, Erdjument-Bromage $\mathrm{H}$, Geromanos S, Tempst $\mathrm{P}$, et al. SNAP receptors implicated in vesicle targeting and fusion. Nature 1993;362:318324.

41. Edelmann L, Hanson PI, Chapman ER, Jahn R. Synaptobrevin binding to synaptophysin: a potential mechanism for controlling the exocytotic fusion machine. EMBO J 1995;14: 224-231.

42. Alder J, Kanki H, Valtorta F, Greengard P, Poo MM. Overexpression of synaptophysin enhances neurotransmitter secretion at Xenopus neuromuscular synapses. J Neurosci 1995; 15:511-519.

43. Clayton DF, George JM. The synucleins: a family of proteins involved in synaptic function, plasticity, neurodegeneration and disease. Trends Neurosci 1998;21:249-254.

44. Kaplan B, Ratner V, Haas E. Alpha-synuclein: its biological function and role in neurodegenerative diseases. $\mathrm{J}$ Mol Neurosci 2003;20:83-92.

45. Liu S, Ninan I, Antonova I, Battaglia F, Trinchese F, Narasanna A, et al. Alpha-Synuclein produces a long-lasting increase in neurotransmitter release. EMBO J 2004;23: 4506-4516.

46. Burré J, Sharma M, Tsetsenis T, Buchman V, Etherton MR, Südhof TC. Alpha-synuclein promotes SNARE-complex assembly in vivo and in vitro. Science 2010;329:1663-1667.

47. Abeliovich A, Schmitz Y, Fariñas I, Choi-Lundberg D, Ho WH, Castillo PE, et al. Mice lacking alpha-synuclein display functional deficits in the nigrostriatal dopamine system. Neuron 2000;25:239-252.

48. Cabin DE, Shimazu K, Murphy D, Cole NB, Gottschalk W, McIlwain KL, et al. Synaptic vesicle depletion correlates with attenuated synaptic responses to prolonged repetitive stimulation in mice lacking alpha-synuclein. J Neurosci 2002;22:8797-8807.

49. Murphy DD, Rueter SM, Trojanowski JQ, Lee VM. Synucleins are developmentally expressed, and alpha-synuclein regulates the size of the presynaptic vesicular pool in primary hippocampal neurons. J Neurosci 2000;20:3214- 
3220.

50. Frasca A, Fumagalli F, Ter Horst J, Racagni G, Murphy KJ, Riva MA. Olanzapine, but not haloperidol, enhances PSA-NCAM immunoreactivity in rat prefrontal cortex. Int $J$ Neuropsychopharmacol 2008;11:591-595.

51. Büttner B, Reutter W, Horstkorte R. Cytoplasmic domain of NCAM 180 reduces NCAM-mediated neurite outgrowth. $J$ Neurosci Res 2004;75:854-860.

52. Dityatev A, Dityateva G, Schachner M. Synaptic strength as a function of post- versus presynaptic expression of the neural cell adhesion molecule NCAM. Neuron 2000;26:207217.

53. Polo-Parada L, Bose CM, Plattner F, Landmesser LT. Distinct roles of different neural cell adhesion molecule
(NCAM) isoforms in synaptic maturation revealed by analysis of NCAM $180 \mathrm{kDa}$ isoform-deficient mice. J Neurosci 2004;24:1852-1864.

54. Doherty P, Fazeli MS, Walsh FS. The neural cell adhesion molecule and synaptic plasticity. J Neurobiol 1995;26:437446.

55. Jeannotte AM, Sidhu A. Regulation of the norepinephrine transporter by alpha-synuclein-mediated interactions with microtubules. Eur J Neurosci 2007;26:1509-1520.

56. Jeannotte AM, McCarthy JG, Redei EE, Sidhu A. Desipramine modulation of alpha-, gamma-synuclein, and the norepinephrine transporter in an animal model of depression. Neuropsychopharmacology 2009;34:987-998. 